\title{
The conservation status of the Chinese alligator
}

\author{
John Thorbjarnarson and Wang Xiaoming
}

\begin{abstract}
The Chinese alligator Alligator sinensis is one of the world's most endangered reptiles. At one time widespread throughout much of the lower Yangzi River basin, the remaining wild individuals are now restricted to a small area in southern Anhui Province and perhaps in adjacent Zhejiang Province. Population estimates conducted in the 1980s suggested that only 500-735 wild individuals remained at that time. Current figures suggest that the wild population is c. 400 individuals and continues to decline. The principal factor contributing to historic population decline has been habitat loss, but deliberate killing of alligators and the heavy use of pesticides have also had significant
\end{abstract}

negative effects. The current conservation programme in Anhui Province is based on captive breeding and the establishment of a reserve for small groups of wild alligators. However, the inferred recent decline in the size of the wild population suggests that the reserve design is inadequate for the long-term survival of alligators. Programmes to survey the status of the remaining wild populations and evaluate the feasibility of establishing new wild populations by reintroducing captive-bred animals are currently being developed.

Keywords China, Chinese alligators, conservation, reptiles, status.

\section{Introduction}

The Chinese alligator Alligator sinensis is the most endangered of the world's 23 species of crocodilians and is listed as Critically Endangered by IUCN (1996). Locally referred to as Yang $\mathrm{Zi} \mathrm{E}$ (Yangzi alligator) or Tu Long (muddy dragon), the alligator was once widespread in the lower Yangzi River valley (formerly the Yangtze and also referred to as the Chang Jiang) and the lower Shaoxing River (Fig. 1). Currently, it is restricted to a few small, isolated areas in southern Anhui Province and adjacent Zhejiang Province (Fig. 2). The Chinese Government began a conservation programme in the late 1970s and early 1980s by establishing a captive breeding centre (Anhui Research Centre for Chinese Alligator Reproduction; ARCCAR) and a reserve for the protection of the remaining wild animals (Thorbjarnarson, 1992). This report summarizes the conservation situation for Chinese alligators based on a review of the literature, and the results of a visit to the area in August 1997. During this trip the authors visited the breeding centres in Anhui and Zhejiang Provinces, the National Chinese Alligator Reserve, and interviewed the staff members of the Anhui Provincial

John Thorbjarnarson (corresponding author) Wildlife Conservation Society, 185th St. and Southern Blvd., Bronx, NY 10460, USA. Fax: +1718 364 4275; e-mail: jcaiman@aol.com

\footnotetext{
Wang Xiaoming Department of Biology, East China Normal University, Shanghai 200062, People's Republic of China. E-mail: wxming@public3.sta.net.cn
}

Forestry Department, and the local Forestry Bureaus in Ma'anshan County, Anhui Province, Changxing County, Zhejiang Province and Yixing County, Jiangsu Province.

\section{Past distribution}

Chinese alligators were widely distributed in lowland areas of eastern China until the recent historical past. Chen (1990) reported Neolithic fossil evidence of Chinese alligators from a number of sites in eastern China including Shandong, Shanghai, Zhejiang and Anhui Provinces, and suggested that global cooling may have played a significant role in eliminating northern populations.

The long record of human history in China indicates that alligators were widely distributed in the lower Yangzi and Shaoxing River valleys, to approximately $32^{\circ} \mathrm{N}$, probably as recently as the mid-nineteenth century (Chen et al., 1985; Chen, 1990; Jinzhong, 1994). Along the Yangzi, alligators were found from the mouth of the river at Shanghai to as far upstream as the vicinity of Jiangling in Hubei Province, where the river flows through the mountainous Three Gorges region. Alligators were found in the extensive wetlands along the river and its tributaries in Hubei, northern Hunan, northern Jiangxi, Anhui and Jiangsu Provinces. In Zhejiang Province alligators were found near the southern margin of the large Tai Hu lake as well as in the Shaoxing River, which empties into Hangzhou Bay (Chen, 1990). 
Fig. 1 The lower Yangzi River valley showing the reconstructed historical distribution of Chinese alligators (shaded area).

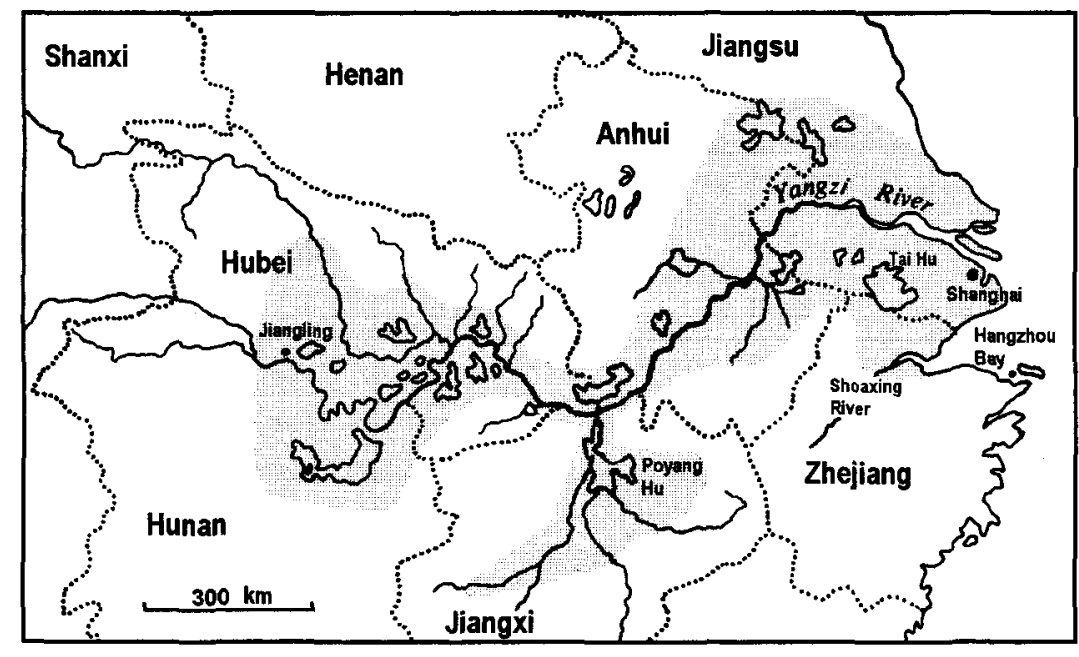

South of the Yangzi, the alligator reportedly became extinct in the Hangzhou Bay region in AD 1201 (Chen, 1990). Around Nanjing, alligators were exterminated in the 1870 s after their burrows in dykes led to widespread flooding. Fauvel (1879) reported that alligators were found in the Yangzi near Chinkiang (= Zhenjiang; Jiangsu Province) and Wuhu (Anhui Province). Others commented to Fauvel that alligators were common in the Poyang Hu lake (Jiangxi Province). Old historical references to crocodilians in Guangdong Province (Fauvel, 1879) probably referred to the saltwater, or estuarine, crocodile Crocodylus porosus or even Tomistoma schlegelii (Zhao et al., 1986). In northern Zhejiang Province, Huang et al. (1987) reported historical records from the following counties: Changxing, Anji, Huzhou, Jiaxing, Yuhang and Hangzhou.

By the 1950s, the distribution of the alligator had been reduced to the region along the southern bank of the Yangzi, extending from Pengze (Jiangxi Province) to the north-western Zhejiang and south-eastern Jiangsu Provinces, with the largest populations in southern Anhui Province (Chen, 1990, 1991).

\section{Present distribution and population status}

Chinese alligators are now restricted to a small area in southern Anhui Province and possibly in neighbouring Zhejiang Province (Fig. 2). Watanabe (1982) suggested that alligators were present in the most north-western part of Jiangxi Province (Pengze) but current sources indicate that alligators were extirpated from this area in the late 1950s (W. Xie, pers. comm.). Some evidence also indicates that alligators may still exist in a small area in the extreme of south-west of Jiangsu Province (see below).

In Anhui, alligators are found principally in river valleys set among the low foothills south of the Huang Shan mountains in five counties (Nanling, Jinxiang, Guangde, Langxi, Xuancheng), which together comprise the National Chinese Alligator Reserve (see below). Staff of the Anhui Forestry Department have also reported small numbers $(<5)$ of alligators outside the reserve at single sites in each of two adjacent counties (Wuhu and Ninggua; Fig. 2). Alligators are still reported in two additional areas in lowland habitat near the Yangzi River. In 1995, an adult male alligator was found in Ma'anshan County in eastern Anhui along the Yangzi River. Alligators have also been reported by villagers at one site in Dangtu County (Fig. 2).

In Zhejiang Province alligators may survive in Changxing County in the Tai Hu lake drainage. As recently as 1976, three alligators were captured in Huzhou County and sent to Ningbo Zoo (Huang et al., 1987), but now alligators are reported to be extirpated in the area. In September 1983, local residents in Anji County collected 18 eggs from a wild nest (Huang et al., 1987). Recent reports of animals in Anji County could not be confirmed by the Changxing Forest Bureau staff.

Staff of the Yixing County Forest Bureau (Xu Ren Yu, pers. comm.) reported that in 1995 a fisherman captured a small $(50-60 \mathrm{~cm}$ total length [TL]) alligator in Yang Hung village, Jiangsu Province. However, no other reports of alligators have been received from this region for the last 10 years.

Alligators are extremely secretive and hard to count. Night spotlight surveys reveal a small number of animals, but many may be hidden in underground dens. Most contemporary sightings and reports are of single individuals or small groups $(<20)$ at each locality. Some of the best information currently available comes from reports by local residents and Forestry Department staff living in the reserve. Based on interview 


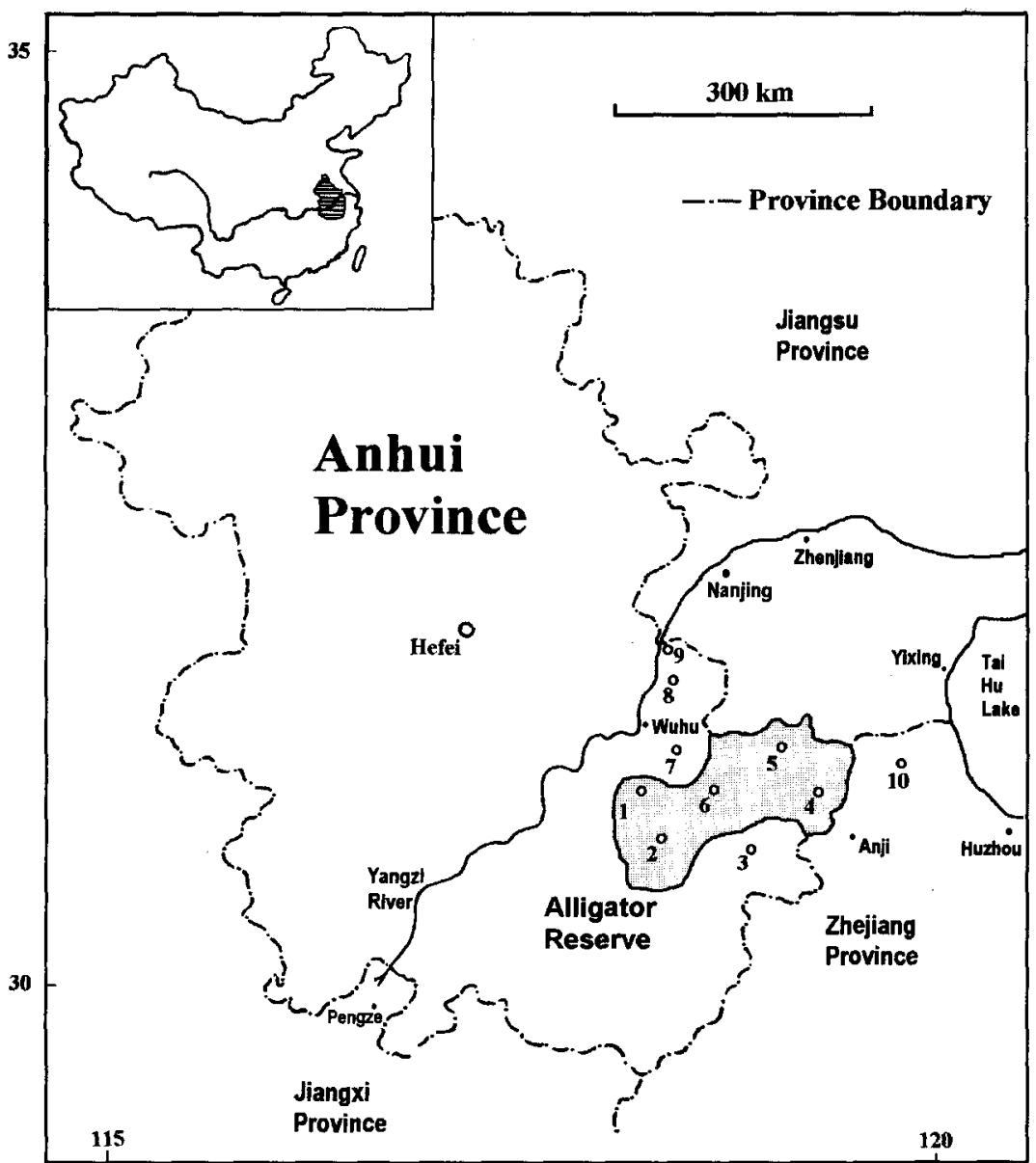

Fig. 2 Map of Anhui Province showing the relative locations of nine counties where Chinese alligators survive. The only other known site is in adjacent Zhejiang Province. 1, Nanling; 2, Jinxiang; 3 , Ninggua; 4, Guangde; 5, Langxi; 6 , Xuancheng; 7, Wuhu; 8, Dangtu; 9, Ma'anshan; 10, Changxing (Zhejiang Province). surveys in the early $1980 \mathrm{~s}, \mathrm{~B}$. Chen estimated that approximately 500 alligators remained in the wild (Anon., 1991). Another more extensive survey of 129 villages (423 bodies of water) was organized by the Anhui Forestry Department in 1985 and 1987. It was estimated that there were $c .735$ alligators remaining in the area of the reserve, with an additional 70 or so in adjacent Zhejiang Province (Anon., 1991). However, the Anhui Forestry Department currently estimates that the total wild population is only 400 individuals (Anhui Forestry Department, 1996; Wen et al., in press).

\section{Factors contributing to population decline}

The principal factor contributing to the decline of the species has been habitat loss. Historically, the middle and lower Yangzi had at one time large expanses of wetland marsh and lake habitat. From the late sixteenth century to the early twentieth century (Quing Dynasty), large numbers of people migrated from the north into the lowland Yangzi region (Huang, 1982; Chen, 1990), resulting in the conversion of the river's floodplain into agricultural fields. Virtually the entire area is now under cultivation (Watanabe, 1982). The last remaining populations of alligators in Anhui Province are in areas south of the Yangzi River where intensive agriculture did not begin until the 1950s and 1960s. Much of the area was marshy with a tendency to flood, and it was only after the installation of adequate water control structures that large numbers of people (mostly from northern Anhui Province) moved into the region. $\mathrm{Hu}-$ man population densities in this area are much lower than in northern Anhui Province, but have increased dramatically since the 1930s (Table 1), and habitat is still being lost. From the 1950 s through to the 1980 s, it was estimated that the total area of lakes in China was reduced by 11 per cent, and that the problem was most severe in the lower Yangzi valley region (Scott, 1989).

Programmes to eradicate schistosomaiasis began in 1958, resulting in the application of sodium pentachlorophenate to agricultural fields, which killed alli- 
Table 1 Human population size and density in seven counties in southern Anhui Province in 1983 and increase in population size since 1935

\begin{tabular}{lllll}
\hline & \multicolumn{2}{l}{1983} & & \\
\cline { 2 - 3 } County & Population & Density (no./sq km) & Area & Per cent increase \\
\hline Dangtu & 601,440 & 429.91 & 1399 & 195.63 \\
Nanling & 433,300 & 342.80 & 1264 & 173.51 \\
Xuancheng & 723,000 & 285.43 & 2533 & 148.72 \\
Langxi & 278,000 & 251.58 & 1105 & 201.99 \\
Guangde & 447,000 & 206.47 & 2165 & 243.90 \\
Ninggua & 340,114 & 138.99 & 2447 & 237.13 \\
Jinxiang & 335,828 & 163.10 & 2059 & 153.96 \\
\hline
\end{tabular}

Source: Zhao \& Xie (1988). gators and their prey. Even before this, from 1949, large amounts of chemical fertilizers and pesticides were used in cultivated fields, reducing or in some cases virtually eliminating the invertebrate prey base for young alligators (Chen, 1990).

The loss of natural vegetation throughout eastern China has also exacerbated periods of drought and flooding. It is thought that large numbers of alligators drowned in their burrows along the Yangzi River during floods in the winter of 1957 (Watanabe, 1982). Flood and drought may also force alligators to move overland where they are easily captured or killed (Chen, 1990). In 1987, a severe drought led to the death of 80 alligators in Langxi County (Zhou, 1997).

Alligators have long been killed by people for a variety of reasons. The earliest Chinese classics mention that the skins of alligators were used for drums in the palaces of the emperors (Fauvel, 1879). Alligators are not tolerated by local farmers because they prey on domestic animals (particularly ducks), and their burrowing interferes with the complex water control structures that are vital for rice cultivation. Historical records suggest that during the Ming Dynasty (13681644) large numbers of alligators were trapped and killed because of their burrowing. However, while alligator skin and meat are considered to have use in traditional Chinese medicine, during most of the nineteenth and twentieth centuries alligators were not eaten by people. If an alligator was killed it was usually chopped up and fed to ducks or pigs (Webb \& Vernon, 1992). However, B. Chen (pers. comm.) reports that after 1986 people in Anhui began eating alligator meat, believing claims that it was dragon meat.

During the 1950s many young alligators were reportedly collected from Zhejiang and Jiangsu Provinces under the direction of the Shanghai Zoo, with many of them being sent to the former USSR ( $B$. Chen, pers. comm.). There is also recent evidence of alligators being purchased by people, presumably to sell the meat. In early August 1997, a man in Yuhang County, Zhejiang Province, was found to have a $1.6 \mathrm{~m}$ TL alligator that he had illegally purchased in Anhui Province.

Chen (1990) found a sharp reduction in the number of alligator eggs that were collected from the wild, suggesting a continuing decline in alligator populations. After the local reserve was established, the Anhui Research Centre for Chinese Alligator Reproduction (ARCCAR) was paying people to collect eggs (most came from Nanling and Xuancheng), yet the numbers fell from 270 to 85 between 1982 and 1985. In 1986, the region was declared a national reserve and paying for egg collection was no longer allowed. However, the collection of eggs from wild nests has continued with 1-5 nests brought to the breeding centre annually (Fig. 3).

\section{Conservation action taken}

Alligators were declared a Class- 1 protected species by the Chinese Government in 1972. However, despite official protection, many animals were still killed or removed from the wild to be placed in captivity

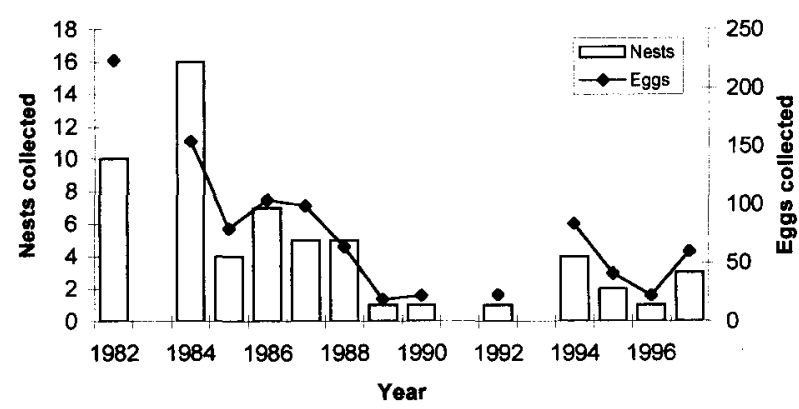

Fig. 3 The total number of nests and eggs of Chinese alligators collected from the wild nests in the National Chinese Alligator Reserve. From Wen et al. (in press). 
(Watanabe, 1982). The collection of animals for captive rearing programmes stopped in 1983, and reports of deliberate killing of wild animals are now almost non-existent.

A great deal of effort has been devoted to the captive breeding of alligators in China. The ARCCAR, the largest breeding facility and the administrative centre of the Anhui alligator conservation programme, was established in 1979. It is located $5 \mathrm{~km}$ south of Xuancheng city in southern Anhui Province, and covers nearly $1 \mathrm{sq} \mathrm{km}$ of a former pine plantation. The original breeding stock of alligators at ARCCAR was 212 animals collected from the wild during the period 1979-82. The ARCCAR initially had difficulty establishing effective breeding and husbandry protocols for alligators (Watanabe, 1982). However, after 1983 breeding performance increased dramatically (Chen, 1990; Webb \& Vernon, 1992) and the first $F_{2}$ generation alligators hatched in 1988. Current annual egg production (1997) is approximately 2500 eggs from 90 nests (Wen et al., in press).

The lack of adequate funding has been one of the greatest difficulties for the Chinese alligator conservation programme. In the late 1980s and early 1990s, the ARCCAR viewed international trade in alligator products as a potential means of raising funds for the breeding programme. In 1992, the ARCCAR breeding centre was officially registered under CITES, thereby allowing the alligators produced at the centre to be traded internationally under the regulations of CITES Appendix II. However, since then, little trade has taken place as a result of the lack of international demand for Chinese alligator skins or live animals. Over the last 3 years the ARCCAR has turned increasingly to the promotion of local tourism to generate funds for the support of the captive breeding centre (W. Xie, pers. comm.).

In 1982, in southern Anhui Province an alligator reserve was established covering a 433-sq-km region of rice and tree farming settlements in five counties. In 1986, this area was upgraded to a national reserve, known as the National Chinese Alligator Reserve. The reserve, with 13 small protected sites, contains the largest known groups of alligators (Table 2; Fig. 3). The number of alligators at any one site is not thought to exceed 20 individuals. Very small groups of alligators, in some cases as few as one or two individuals, are known from other areas within the reserve (Fig. 4).

The administration of the reserve is managed by the ARCCAR, which employs a programme co-ordinator in each of the five counties and local caretakers at each of the 13 protected sites. However, because the land at each site belongs to local agricultural
Table 2 List of the 13 protected stations (by county) in the National Chinese Alligator Reserve

\begin{tabular}{|c|c|c|}
\hline County & Site & River system \\
\hline 1. Nanling & $\begin{array}{l}\text { A. Xi Feng } \\
\text { B. Chang Li } \\
\text { C. Zha Lin }\end{array}$ & $\begin{array}{l}\text { Zhang He } \\
\text { Qing Yi He } \\
\text { Zhang He }\end{array}$ \\
\hline 2. Jinxiang & $\begin{array}{l}\text { D. Yan Tang } \\
\text { E. Shuang Ken } \\
\text { F. Zhong Qiao }\end{array}$ & $\begin{array}{l}\text { Qing Yi He } \\
\text { Qing Yi He } \\
\text { Zhang } \mathrm{He}\end{array}$ \\
\hline 6. Xuancheng & $\begin{array}{l}\text { G. Hong Xin } \\
\text { H. Yang Lin }\end{array}$ & $\begin{array}{l}\text { Qing Yi He } \\
\text { Shui Yang He }\end{array}$ \\
\hline 5. Langxi & $\begin{array}{l}\text { I. Wang Jia Meu } \\
\text { J. Zhang Cun } \\
\text { K. Huang Shu Gang }\end{array}$ & $\begin{array}{l}\text { Lang Chuan He } \\
\text { Lang Chuan He } \\
\text { Lang Chuan He }\end{array}$ \\
\hline 4. Guangde & $\begin{array}{l}\text { L. Jia Gu } \\
\text { M. Zhu Cun }\end{array}$ & $\begin{array}{l}\text { Lang Chuan } \mathrm{He} \\
\text { Lang Chuan } \mathrm{He}\end{array}$ \\
\hline
\end{tabular}

Numbers for counties are those indicated in Figs 2 and 4; letters for each site are those indicated in Fig. 4

communes, the ARCCAR has limited authority over land-use issues in the areas surrounding the remnant groups of alligators.

Although the reserve is fairly large, alligators are restricted to tiny water bodies at widely separated sites within an almost completely agricultural area. The human population of the five-county region is 2.2 million (average density 243 people/sq $\mathrm{km}$ ) and has grown considerably in recent decades (Table 1).

Most alligators are found in two major habitat types: ponds in the densely populated river valleys; or small reservoirs set in the hills that define the valleys. In the river valleys land is heavily cultivated, principally for rice. Most ponds are small ( $<$ $500 \mathrm{sq} \mathrm{m}$ ), rectangular or polygonally shaped bodies of water set amongst rice fields, while others are long, narrow drainages. Although human population densities are lower around the hill reservoirs, the land is still used intensively for cultivation of rice and other crops (around the reservoirs) and trees and tea on the surrounding hills.

At each of the 13 sites (Fig. 4), the only areas actually protected are the ponds themselves. In some cases there is little or no vegetation fringe between the water and the cultivated fields, and under these conditions, conflicts between people and alligators are inevitable. Alligators seek refuge and hibernate in burrows excavated into the banks of ponds, but digging even a small distance into the shores of ponds will take alligators into agriculture fields. Moving between ponds usually means walking through rice fields. Ducks and other domestic animals use the edges of these ponds and are potential prey for all 
Fig. 4 Map of the National Chinese Alligator Reserve showing the relative locations of the 13 principal alligator sites and other areas where alligators have been reported. Numbers are the county capitals as in Fig. 1. Letters refer to the individual protected sites as listed in Table 2.

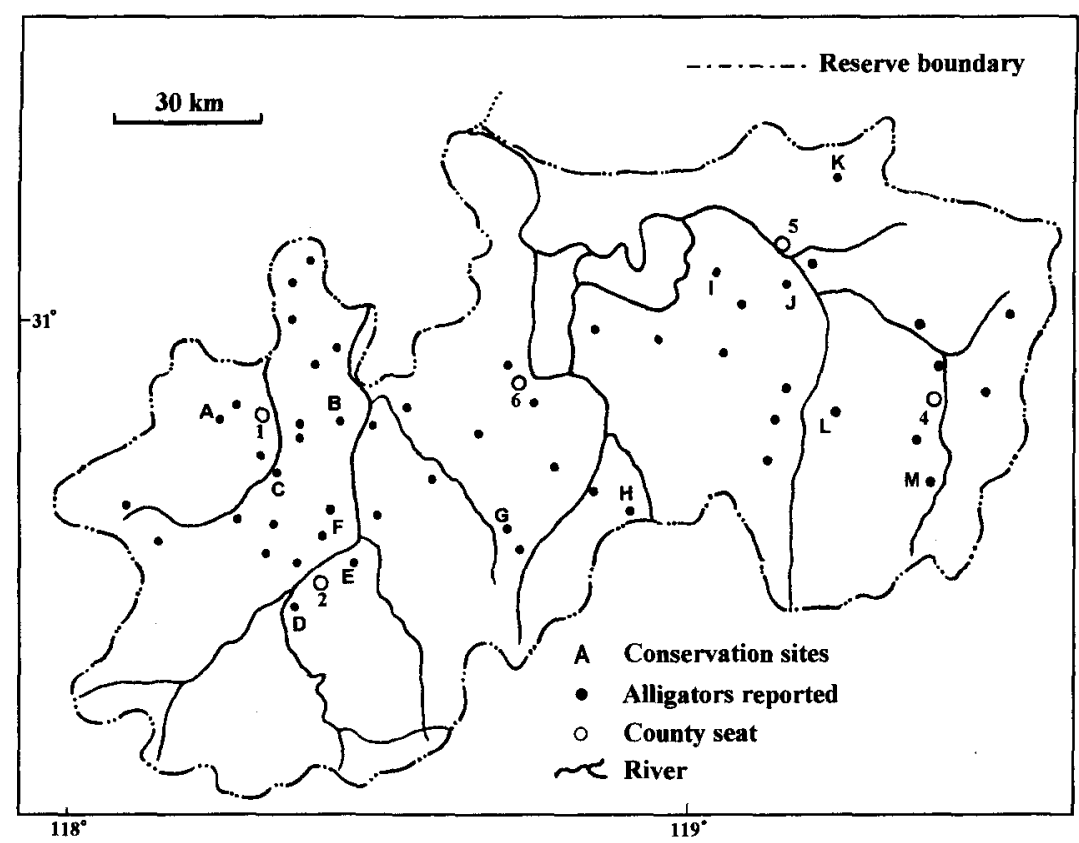

The main focus of the Chinese conservation progators. Under these marginal habitat conditions, the presence of islands may be one of the key factors that determines alligator survival. Small islands may act as a buffer from human impacts because they offer a relatively undisturbed area for alligators to dig burrows and nest.

Despite the designation of the reserve and the protection of the ponds where the alligators live, available evidence suggests that the wild population continues to decline. Estimated numbers of alligators in the wild have fallen since the 1980s (see above). In one documented case, the alligator population at one site (Hong Xin) fell from 14 to seven between 1992 and 1995 (Zhu, 1997).

\section{Discussion}

The Chinese alligator is an animal without a habitat. Centuries of conversion of the wetland habitats in the Yangzi lowlands to agricultural use have pushed alligators into their last remaining corner in southern Anhui Province. This was one of the last areas in the lower Yangzi valley to be developed for agriculture, with a major human population influx occurring during the 1950s. In this region alligators remain in tiny groups in interstitial ponds intimately associated with the growing human settlements. Alligators still exist here in the 'wild', due in large part to relatively recent initiation of intensive agriculture, and the longevity and the extremely secretive habits of the alligators. The irony of the current situation is that the alligators in many of the ponds at the ARCCAR breeding centre live in a more natural habitat than those left in the wild. gramme has been captive breeding, which has proven to be extremely successful. Due to the efforts of the captive breeding programmes in Anhui and Zhejiang Provinces, as well as other breeding centres in China and parallel efforts in zoos in the USA (Behler, 1977, 1993), the Chinese alligator is in no real danger of becoming extinct. Nevertheless, the situation for the few remaining wild individuals is critical. The last remnant populations are small and isolated from one another, and most evidence suggests that populations continue to decline, so the long-term viability of these groups is questionable.

Efforts to ensure the continued survival of the Chinese alligator in the wild need to focus on two main issues: improving the long-term viability of each of the remnant populations; and determining the feasibility of establishing new populations based on the release of captivereared alligators. Most urgently the viability of existing populations needs to be enhanced through a series of measures to improve the quantity and the quality of the habitat at sites where alligators remain. Measures that involve land-use issues will require close collaboration with local communities in all aspects from planning to implementation and monitoring. Buffer zones of natural vegetation around ponds and linking neighbouring ponds are fundamental for reducing alligator-people conflicts, as well as creating adequate habitat for successful nesting and space for a mixed-age population of alligators. The creation of small islands in ponds may have a particularly beneficial impact by providing secure places for alligators to bask and nest.

The effects of environmental contaminants on alliga- 
tors will have to be examined closely. In the USA, pesticides and other chemicals have been linked to reduced egg viability and compromised reproductive systems in American alligators (Jennings et al., 1987; Guillette et al., 1994). The prevalent use of pesticides and other chemicals in fields around the ponds inhabited by Chinese alligators may have direct effects on alligators. Indirect threats, such as eliminating or reducing the invertebrate prey base of juvenile alligators, may also be a consequence of environmental contamination.

At present, it is thought that the largest of the existing groups of Chinese alligators numbers less than 20 individuals. Populations this small are at the mercy of a large number of stochastic factors that reduce long-term population viability. Environmental extremes, such as drought, or major winter flooding, could eradicate alligators from one or more sites. Each site may not have more than one or two females, and genetic interchange among groups is highly unlikely because of their isolation. Under these conditions problems related to genetic drift and inbreeding depression may be severe, and long-term survival may depend on active intervention by Chinese wildlife authorities to increase the genetic variability of each subpopulation. Demographic stochasticity may also be a factor, particularly because sex determination in alligators is temperature-dependent (Lang \& Andrews, 1994) and the nesting habitats that remain are highly altered. If forced to nest in sites that produce temperature extremes, populations may be highly sex-biased.

The potential for the creation of new populations by releasing captive-bred individuals remains unknown. Certainly, there is no lack of captive alligators that can be used, but the availability of suitable areas for releases, and how alligators adapt following release would have to be determined as part of a trial management programme. Ecological studies of existing populations are also a high priority, particularly ones that focus on: the size and demographic structure of remaining populations; habitat preferences and how they vary ontogentically; diet and food availability; the growth, body condition and health of wild alligators; genetic variability within and between subpopulations; and levels of contaminants in both the ponds and the alligators themselves.

Human impacts on the last remaining groups of alligators necessitate a firm commitment to conservation on the part of the National and Provincial Governments, as well as the active co-operation of the local communities. The latter will need to be built upon programmes of public education, and pragmatic attempts to increase the value of alligators to affected farming communities. In this respect, two options seem most viable: paying farmers for protection measures; and ecotourism. The promotion of wildlife tourism could be directed toward the increasing number of Chinese tourists, as well as foreign visitors, many of whom visit Shanghai or take trips on the Yangzi River. While most of the high-profile endangered species in China, such as the giant panda and the Yangzi River dolphin, are very difficult to observe, under the proper conditions tourists could be virtually guaranteed the sight of a wild Chinese alligator. A well-managed ecotourism programme could generate economic benefits to the farming communities as well as the Anhui Provincial Forestry Department, and could be reinvested into alligator conservation.

Under a joint programme between the Anhui Forestry Department, the East China Normal University and the Wildlife Conservation Society, plans are being developed to conduct status surveys of the remaining wild populations. Surveys will establish the basis for initiating ecological studies of specific groups of wild alligators, and the information will be used by the Anhui Provincial Government to evaluate the long-term viability of the wild populations. The Provincial Government and the ARCCAR are also committed to the idea of using captive-bred alligators to establish new wild populations, and have developed a draft management plan that places considerable emphasis on the release of alligators into new sites (Anhui Forestry Department, 1996; Kui Chu Shi, pers. comm.).

\section{Acknowledgements}

In Anhui Province we were hosted by the Anhui Provincial Government, and the following people who allowed us to visit the National Chinese Alligator Reserve and generously provided information on alligators: Kui Chu Shi, Director, Anhui Forestry Department; Gu Chang Ming, Anhui Forestry Department and Anhui Wildlife Conservation Association; Xie Wan-Shu, Director, Anhui Research Centre of Chinese Alligator Reproduction; Wang Chao Lin, Vice-Director, ARCCAR. In Changxing County, Zhejiang Province: Wang Zhi Ping, Director of the County Forest Bureau; and in Yixing County, Jiangsu Province, $\mathrm{Xu}$ Ren $\mathrm{Yu}$ provided much helpful information. We also are indebted to Professor Chen Bihui who generously shared his knowledge of Chinese alligators with us, and Professor Sheng Helin who assisted us in every way during our trip. Funding was provided by the Wildlife Conservation Society.

\section{References}

Anhui Forestry Department (1996) Draft Management Programme for Chinese Alligator in Anhui Province. Hefei, Anhui Province. 
Anon. (1991) Registration of the Anhui Research Centre of Chinese Alligator Reproduction for Alligator sinensis. Proposal to CITES. Kyoto, Japan.

Behler, J.L. (1977) A propagation program for Chinese alligators (Alligator sinensis). Herpetological Review, 84, $124-125$.

Behler, J.L. (1993) Chinese alligator (Alligator sinensis). AAZPA Annual Report on Conservation and Science. 1992-1993, pp. 227-229.

Chen, B.C. (1990) The past and present situation of the Chinese alligator. Asiatic Herpetological Research, 3, 129-136.

Chen, B. (1991) Chinese alligator. In The Amphibian and Reptilian Fauna of Anhui (ed. B. Chen), pp. 361-365. Anhui Publishing House of Science and Technology, Hefei, Anhui, China [in Chinese].

Chen, B., Hua, Z. \& Li, B. (1985) Chinese Alligator. Anhui Science and Technology Press, Hefei, Anhui, China [in Chinese].

Fauvel, A.A. (1879) Alligators in China. Journal of the North-China Branch of the Royal Asiatic Society, Shanghai New Series, 13, 1-36.

Guillette, L.J., Jr., Gross, T.S., Masson, G.R., Matter, J.M., Percival, H.F. \& Woodward, A. (1994) Development abnormalities of the gonad and abnormal sex hormone concentrations in juvenile alligators from contaminated and control lakes in Florida. Environmental Health Perspectives, 102, 680-688.

Huang, C. (1982) The ecology of the Chinese alligator and changes in its geographical distribution. In Crocodiles. Proceedings of the 5th Working Meeting of the IUCN/SSC Crocodile Specialist Group, pp. 54-62. IUCN, Gland, Switzerland.

Huang, M., Jin, Y. \& Cai, C. (1987) Fauna of Zhejiang. Zhejiang Science and Technology Publishing House, Hangzhou, Zhejiang, China [in Chinese].

IUCN (1996) 1996 IUCN Red List of Threatened Animals. IUCN, Gland, Switzerland.

Jennings, M.L., Percival, H.F. \& Abercrombie, C.L. (1987) Habitat variables affecting nesting success of the American alligator in Florida. Proceedings of the Annual Conference of Southeast Association Fish and Wildlife Agencies, 41, 334-342.

Jinzhong, F. (1994) Conservation, management and farming of crocodiles in China. In Crocodiles. Proceedings of the $2 n d$ Regional (Eastern Asia, Oceania and Australasia) Meeting of the Crocodile Specialist Group. IUCN-The World Conservation Union, Gland, Switzerland.

Lang, J.W. \& Andrews, H.V. (1994) Temperature-dependent sex determination in crocodilians. The Journal of Experimental Zoology, 270, 28-44.

Scott, D.A. (compiler) (1989) A Directory of Asian Wetlands. IUCN-The World Conservation Union, Gland, Switzerland.
Thorbjarnarson, J.B. (compiler) (1992) Crocodiles: an Action Plan for their Conservation. IUCN-The World Conservation Union, Gland, Switzerland.

Wen, Z., Gu, C., Wang, X. and Wang, C. (in press) Conservation, management and farming of crocodiles in China. In Crocodiles. Proceedings of the 14th Working Meeting of the Crocodile Specialist Group. IUCN-World Conservation Union, Gland, Switzerland.

Watanabe, M. (1982) The Chinese alligator: is farming the last hope? Oryx, 17, 176-181.

Webb, G.J.W. \& Vernon, B. (1992) Crocodilian management in the People's Republic of China-a review with recommendations. In Crocodile Conservation Action. A Special Publication of the Crocodile Specialist Group of the Species Survival Commission of the IUCN-The World Conservation Union, pp. 1-27. IUCN-The World Conservation Union, Gland, Switzerland.

Zhao, K., Zong, Y. \& Ma, J. (1986) On the ancient crocodiles of Guangdong Province. Acta Herpetologica Sinica, 5, 161-165.

Zhao, W.L. \& Xie, S.J. (1988) History of the Chinese Population. People's Press, Beijing [in Chinese].

Zhou, Y. (1997) Analysis of the decline of the wild Alligator sinensis population. Sichuan Journal of Zoology, 16, 137 [in Chinese]

Zhu, H. (1997) Observations on a wild population of Alligator sinensis. Sichuan Journal of Zoology, 16, 40-41 [in Chinese].

\section{Biosketches}

John Thorbjarnarson is a Conservation Zoologist with the Wildlife Conservation Society, based in New York, where he co-ordinates the reptile conservation efforts in the International Programs department. He received his $\mathrm{PhD}$ from the University of Florida in 1991. His main interests are the ecology and conservation of reptiles, particularly crocodilians and turtles. With the SSC Crocodile Specialist Group he compiled the first IUCN/SSC Crocodile Action Plan in 1992. Most of his research has been on New World crocodilians and has included work in Venezuela, Brazil, Belize, the Dominican Republic and Haiti.

Xiaoming Wang is an Associate Professor in the Department of Biology, East China Normal University in Shanghai, P.R. China and Secretary General of the Shanghai Zoological Society. He received his $\mathrm{PhD}$ in Population and Ecology Biology at the University of Montpellier II, France in 1993. His areas of interest include conservation biology, molecular ecology, animal behaviour and ecology of endangered animal populations. 